\title{
INVESTIGATING DIFFERENCES BETWEEN INSTRUCTOR EXPECTATION AND STUDENT WORKLOAD IN UNDERGRADUATE ENGINEERING
}

\author{
Sarah Wentling and Chirag Variawa \\ University of Toronto
}

s.wentling@mail.utoronto.ca and chirag.variawa@utoronto.ca

\begin{abstract}
For the past two years at the University of $X$, first-year engineering undergraduate students have been asked to fill out workload questionnaires. These questionnaires were sent to random samples of the first-year class weekly, where they were prompted to answer questions regarding how much time they devoted outside of the classroom to each particular class. Workload data for 2018 and 2019 showed upward of 30 hours of work outside of the classroom, after the first few weeks of classes once major assignments and examinations began. Evidence in the literature [1,2] suggests that university students face a shortage of time, specifically with first-year students lacking the essential time management skills to be efficient.

In the present study, we aim to find a correlation between how long the first-year engineering students spend on a class each week versus how long instructors anticipate the average student would spend on their respective class. In order to do so, we examined the data gathered for 2018 and 2019 fall terms from each student for a specific class and week. Furthermore, additional relevant information will be gathered from the instructors and course coordinators to obtain an estimate on how many anticipated hours a student would have to spend on their course that week, given what assessments are in that week.
\end{abstract}

Through analyzing multiple courses, we expect to find a relationship that would suggest whether the hours students spend on assignments is less than, equal to, or greater than what instructors expect for first-year engineering students at University of $X$ to spend. The outcome of this analysis would be beneficial to understand the workloads as perceived by professors and experienced by first-year engineering students. Furthermore, it can highlight potential misjudging of difficulty of each course and assignment, helping instructors to update their expectations and propose fair deadlines and grades for assessments. It can also assist program coordinators to distribute major assessments better towards a steadier and more manageable workload for the students. The students can also benefit from the findings to understand their time commitments.

Keywords: Engineering education, workload, time management, perceived time, surveys

\section{INTRODUCTION}

Engineering undergraduate programs in Canada are recognized for their rigorous schedules. The time associated with engineering programs is reflected in the hours that students spend in lecture, tutorials, and laboratories. On top of the hours they spend in class students are expected to complete all assessments and study for their classes in the remaining hours. It has become prevalent that some students feel as if they do not have enough time to complete classwork and participate in extracurriculars outside of the classroom without starting to feel like they are getting behind. Our research looks to examine whether students truly have too much on their plate to balance a healthy lifestyle, looking to see the effect of spending too much time on work and mental health of students. The observations made will help to highlight factors in engineering education including the difficulty of course content, the expectation of the instructor, and potential structural changes that could enhance student experience. It is important for students and instructors to be transparent on expectations of assessments in order to build an accessible environment as students transition to secondary level education.

\subsection{MOTIVATION}

The Canadian Federation of Engineering Students is a group that represents students' needs ranging in professional advice, and aid in enhancing student experience in and out of the classroom. According to Canadian Federation of Engineering Students 
(CFES), engineering programs are known for the demanding nature they place on students [3]. Approximately $61 \%$ of university students worldwide reported feeling pressured, stressed and anxious in school due to not having enough time to complete all of their work $[4,5]$. The CFES has recognized its own the problem as it claims that engineering students have high report rates of degrading mental health merely after first year as a consequence of poor structure in terms of expectation and delegation. Specifically, $80.2 \%$ of the students they surveyed reported the main factor of stress was the amount of workload they had to complete simultaneously [6]. To combat the stress of workload universities have attempted to implemented physical classes, mediation sessions, and activities like coloring and planting, although they have had little effect since students still need time to do such activities [3].

This research discussed in this paper was initiated to provide insight to both professors and students to see if students are overworking themselves or expectations of first year undergraduate engineering students is unmanageable. Looking at both the perspective of the student and the course coordinator could provide insight on ways to change scheduling of assessments, layout of syllabi to incorporate time recommendations, the accessibility of resources to improve time management, and the effect of workload on mental health. Furthermore, the result of the research could help to provide insight to see if students have enough time to attend all lectures, tutorials, and labs, complete all assignments, study for their course, and engage in extra-circulars. Research shows that there is a positive linear relationship between extracurricular activities and traits of good character as defined by Engineers Canada [4,5]. Therefore, time to participate in such activities would be beneficial to the development of an engineering student. Our research will focus on the correlation on how many hours students spend outside the class time on a course each week verse what the course coordinator anticipates the students spend. This research will provide a clearer picture of the demands first year engineering students are faced with. Further, the data will be related to the available amount of time per week and how course coordinator expectations of work outside the classroom influences how students spend their time. The data collected has the potential to inform both students and coordinators about each other's perspectives by showing evidence of the workload that should be completed.
The principal questions initiating this study are:

- Are students spending more than the expected time on work outside of the classroom?

- Is student workload affecting students' abilities to participate in extracurriculars, sleep, and a maintain healthy lifestyle?

- How can the first-year undergraduate engineering community change the culture of the demandingness to improve the mental health of their students?

\subsection{METHODS}

This study considers an aspect of workload through two different perspectives: first-year engineering undergraduate students and the first-year engineering course coordinators. The first-year engineering undergraduate classes have diverse backgrounds of academe and personal experiences, which have helped shape their time management abilities. Each week of classes in the fall and winter term randomly selected students from each of the core eight disciplines were asked to reflect on how many hours they spent outside of class and the difficulties both conceptually and operationally. Once this data was collected course coordinators were asked based off the assignments, quizzes, labs, and midterms given that week in their course how many hours they would expected students should have spent in order to understand and synthesize the course content. Specifically, this study examines week 8 for both Fall 2018 and 2019, of the syllabi since it is in the middle of the semester where students have begun to have larger assessments including midterms and major deliverable projects. This information was collected for five classes as described in Table A. A sample of the weekly survey for one class can be seen in Appendix A.

Further information regarding the amount of time university students need for extra-circular was collected. This information integrated with course coordinators expectation hours provides a story board of available hours and realistic expectations of how many hours students can spend on school.

Lastly in the weekly survey students were asked to give suggestion providing qualitative data, which is insightful to how the students responded to the workload demand for the week. 
Table A - Courses and Topics in Week 8

\begin{tabular}{|c|c|}
\hline $\begin{array}{l}\text { Course- Course } \\
\text { Name }\end{array}$ & $\begin{array}{l}\text { Description of Content in Week } \\
8\end{array}$ \\
\hline $\begin{array}{l}\text { CIV100 - } \\
\text { Statics }\end{array}$ & $\begin{array}{l}\text { Course explores structure } \\
\text { analysis of frames, as machines } \\
\text { and pulleys, and strength of } \\
\text { material regarding the design of } \\
\text { axially loaded bars. }\end{array}$ \\
\hline $\begin{array}{l}\text { MAT186- } \\
\text { Calculus } 1\end{array}$ & $\begin{array}{l}\text { Course explores applications of } \\
\text { the derivative with maximums, } \\
\text { minimums, extreme values, } \\
\text { critical points, increasing, } \\
\text { decreasing, concavity, curve } \\
\text { sketching and optimization } \\
\text { problems. }\end{array}$ \\
\hline $\begin{array}{l}\text { MAT188 - } \\
\text { Linear Algebra }\end{array}$ & $\begin{array}{l}\text { Course explores eigenvalues } \\
\text { and eigenvectors, matrix } \\
\text { diagonalization, systems of } \\
\text { linear differential equations, } \\
\text { and characteristics of } \\
\text { polynomial matrix. }\end{array}$ \\
\hline $\begin{array}{l}\text { APS111 - } \\
\text { Engineering } \\
\text { Strategies and } \\
\text { Practices }\end{array}$ & $\begin{array}{l}\text { Course explores the concepts of } \\
\text { service environment and } \\
\text { stakeholders. }\end{array}$ \\
\hline $\begin{array}{l}\text { APS110-- } \\
\text { Engineering } \\
\text { Chemistry and } \\
\text { Material } \\
\text { Science }\end{array}$ & $\begin{array}{l}\text { Course explores the Bohr } \\
\text { model, electronic configuration, } \\
\text { electromagnetic spectrum, } \\
\text { covalent, ionic, and metallic } \\
\text { bonds, and the band theory of } \\
\text { solids. }\end{array}$ \\
\hline
\end{tabular}

\subsection{RESULTS}

Although, not all data has been synthesized through these box and whisker plot graphs provide some insight and primarily conclusions of the workload study. Each year 2018 and 2019 general overviews are shown together with all of the classes in Figures $\mathrm{A}$ and $\mathrm{B}$ respectively. Then to compare each class by year APS111, CIV100, MAT186, APS110, and MAT188, are shown corresponding as Figure C, Figure D, Figure E, Figure F, and Figure G. All course coordinators have responded giving their input on how many hours they anticipated students spent on assessments in their class in each week as seen in Table B. Furthermore, looking into class difficulty the data's averages can be seen in Table C.
Figure A: 2018 Fall Term Summary

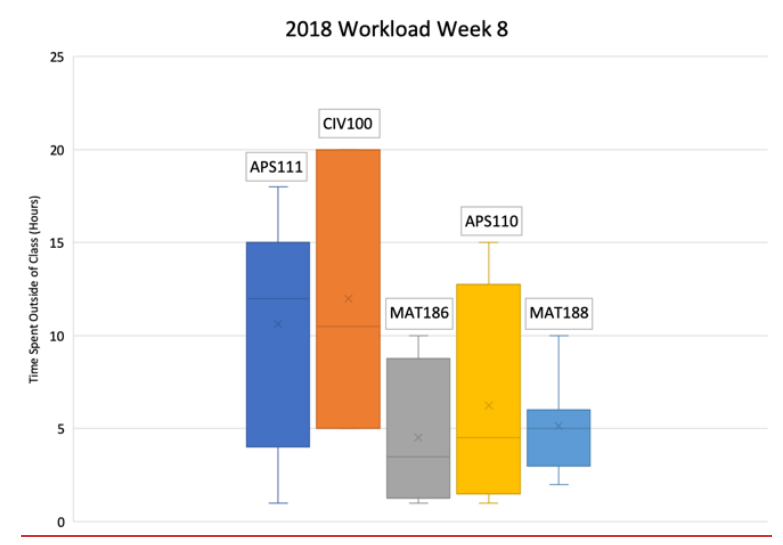

Figure B: 2019 Fall Term Summary

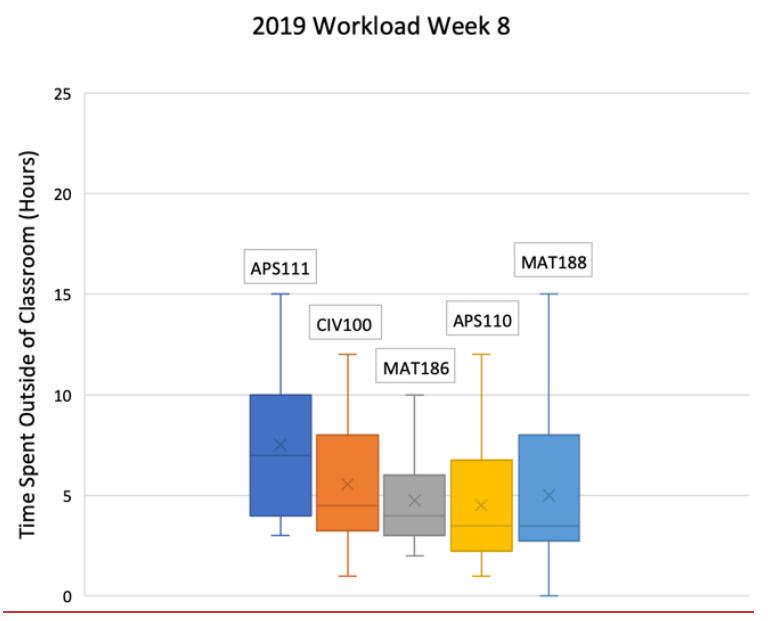

Figure C: APS111 Workload

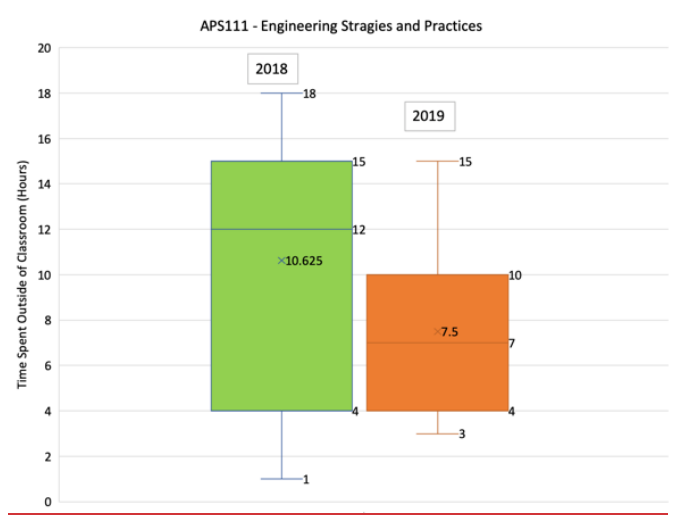


Figure D: CIV100 Workload

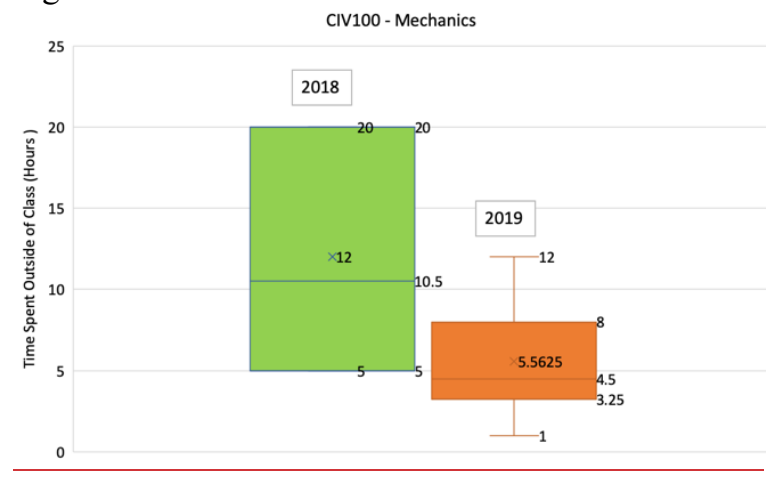

Figure E: MAT186 Workload

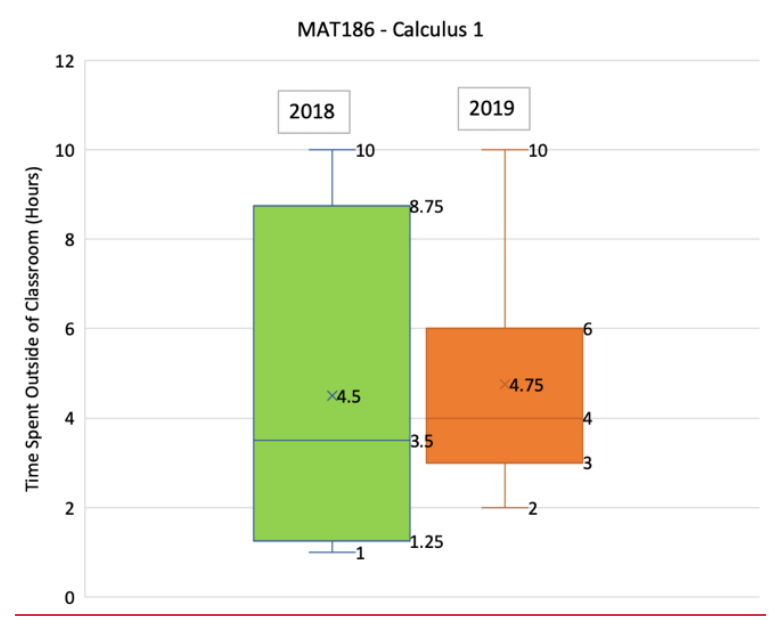

Figure F: APS110 Workload

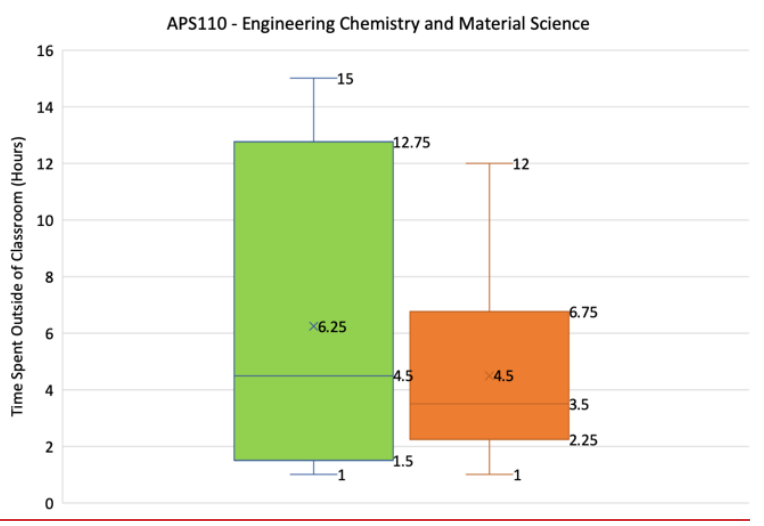

Figure G: MAT188 Workload

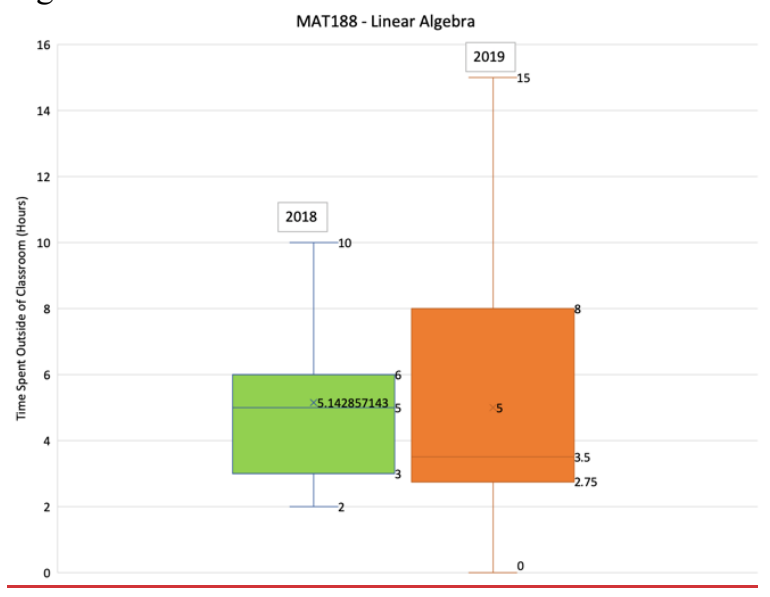

Table B: Course Coordinators expected hours

\begin{tabular}{|l|l|l|}
\hline Course & Assessments & Expected Hours \\
\hline APS111 & $\begin{array}{l}\text { Project } \\
\text { Requirements } \\
\text { Document }\end{array}$ & 8-10hours \\
\hline CIV100 & Midterm & 8-12 hours \\
\hline MAT186 & Quiz & 3-4 hours \\
\hline APS110 & Problem Set & 3-4 hours \\
\hline MAT186 & Quiz & 2 \\
\hline
\end{tabular}

Table C: Difficulty Averages for Fall 2018 and 2019

\begin{tabular}{|l|l|l|l|l|}
\hline Course & $\begin{array}{l}\text { Average } \\
\text { Conceptual } \\
\text { Difficulty } \\
\text { for Week } \\
8,2018\end{array}$ & $\begin{array}{l}\text { Average } \\
\text { Conceptual } \\
\text { Difficulty } \\
\text { for Week } \\
8,2019\end{array}$ & $\begin{array}{l}\text { Average } \\
\text { Operational } \\
\text { Difficulties } \\
\text { for Week } \\
8,2018\end{array}$ & $\begin{array}{l}\text { Average } \\
\text { Operational } \\
\text { Difficulties } \\
\text { for Week } \\
8,2019\end{array}$ \\
\hline APS111 & 3.13 & 4.13 & 3.75 & 4.25 \\
\hline CIV100 & 3.86 & 3.94 & 3.71 & 4.00 \\
\hline MAT186 & 3.25 & 4.00 & 2.75 & 3.85 \\
\hline APS110 & 3.25 & 4.50 & 2.75 & 2.83 \\
\hline MAT188 & 3.75 & 3.93 & 3.63 & 3.71 \\
\hline
\end{tabular}

\subsection{Discussion}

This investigation looked to examine whether students spend the expected hours studying as estimated by the course coordinator. Although more information has to be collected with APS110, Engineering Chemistry and Material Science, the other four classes show primarily results. As for 
MAT186 (Calculus 1) and MAT188 (Linear Algebra), the course coordinators estimated between 3-4 hours for students to properly complete all suggested problems to perform well on their quiz. Although the results showed averages of 4.5 hours (2018) and 4.75 hours (2019) for MAT186, which is 30-45 minutes above the estimated. Meanwhile MAT188 had averages of 5.14 hours (2018) and 5 hours (2019), which was over an hour more than what course coordinators expected. Correspondingly, it was interesting to see that the difficulty levels for MAT188 were higher than MAT186. The qualitative responses also showed that less material was categorized as review material in MAT188, "Distance between lines, planes, and points was review to me but even this was difficult in regard to how it integrates matrices and eigenvectors."

Another first year class, APS111 (Engineering Strategies and Practices) is a design course that involves practical skills and teamwork of 5-6 students showed the highest operational difficulties for each 2018, and 2019 which were 3.75 and 4.25 respectively. The project requirement document involves meeting with a client and coordinating between all students in order to complete the project. While the course coordinator suggested 8-10 outside of class, students responded with averages of 10.625 hours for 2018 and 7.5 hours for 2019. Interestingly the 2019 students responded with higher operational difficulties than the 2018 students but reported approximately 3 hours less outside of the classroom.

Furthermore, the CIV100 (Mechanics) class was the only class with a midterm in week 8 of the syllabus. The reported averages were 12 hours (2018) and 5.5625 hours (2019), while the course coordinator reported an expected 8 to 12 hours. The conflicting results between 2018 and 2019 require deeper investigation on perhaps what the students had as prior knowledge.

The evidence shows that certain course coordinators have a better gauge on the expected hours the students should spend. While some overestimated for some years and underestimated for others.

\subsection{Conclusion}

Moving forward, we will be examining the relationships between the student responses and the course coordinator responses. Furthermore, more work and attention will go into reconciling the quantitative responses with the qualitative responses. Examples of qualitative responses that have the potential to shape our discussion can be seen in
Appendix B. Currently, the primarily results show that course coordinators do have a good estimate of how many hours students should be spending outside of their course. Although, with four out of the five classes with data received already showing 30 hours outside of the classroom needed to complete classwork, the question is if students have that much time to balance the distribution of work. We will also be examining how the level of difficulty in classes could play a role in how many hours students spend outside the classroom. However, this exploratory work is a step towards better understand first-year engineering students' workload in the context of specific course.

\subsection{REFERENCES}

[1] E. Kyndt and I. Berghmans, “"Time is not enough.' Workload in higher education: a student perspective," Higher Education Research \& Development, vol. 33, no. 4, pp. 684-698, Feb. 2013.

[2] H. Kearns and M. Gardiner, "Is it time well spent? The relationship between time management behaviours, perceived effectiveness and work-related morale and distress in a university context," Higher Education Research \& Development, vol. 26, no. 2, pp. 235-247, 2007.

[3] Canadian Federation of Engineering Students Official Stance. (2018). Student Mental Health \& Workload.

[4] Engineerscanada.ca. (2013). Public guideline on good character | Engineers Canada. [online] Available at: https://engineerscanada.ca/publications/publicguideline-on-good-character\#-defining-goodcharacter [Accessed 8 Feb. 2020].

[5] Dalrymple, O. and Evangelou, D. (2006). The Role of Extracurricular Activities in the Education of Engineers. [online] Available at:

http://www.ineer.org/Events/icee2006/papers/3243.p df [Accessed 9 Feb. 2020].

[6] Fidler, J., McGeorge, L. and McLearn, K. (2018). Prevalence and Predictors of Stress and Anxiety Among College Students. [online] Available at: https://digitalcommons.sacredheart.edu/cgi/viewcont ent.cgi? article $=1245 \&=\&$ context $=$ acadfest $\&=\&$ seiredir $=1 \&$ referer $=$ https $\% 253 \mathrm{~A} \% 252 \mathrm{~F} \% 252$ Fscholar.g oogle.com\%252Fscholar\%253Fas_ylo\%253D2016\% 2526q\%253Dstudents\%252Breporting\%252Bstress\% 252Band\%252Baniexty\%252Buniversity\%252B\%25 
26hl\%253Den\%2526as_sdt $\% 253 \mathrm{D} 0 \% 252 \mathrm{C}$ \# $\%$ search $=\% 22$ students $\% 20$ reporting $\% 20$ stress $\% 20$ aniexty $\% 2$

0university\%22 [Accessed 8 Feb. 2020].

\subsection{APPENDIX}

\begin{tabular}{|c|c|}
\hline Question & Type of Response \\
\hline $\begin{array}{l}\text { For Linear Algebra how } \\
\text { much focused time did you } \\
\text { spend on all assignments for } \\
\text { this course outside of class } \\
\text { this week? }\end{array}$ & Enter time in hours \\
\hline $\begin{array}{l}\text { How difficult were these } \\
\text { assignments Conceptually? } \\
\text { (didn't know where to start, } \\
\text { but once started it was easy } \\
\text { to finish) }\end{array}$ & Enter value 1-5 \\
\hline $\begin{array}{l}\text { How difficult were these } \\
\text { assignments Operationally? } \\
\text { (knew where to start, but the } \\
\text { steps to complete it were } \\
\text { challenging and/or tedious) }\end{array}$ & Enter value 1-5 \\
\hline $\begin{array}{l}\text { About how much of this } \\
\text { material is review from } \\
\text { what you knew before } \\
\text { taking this course? }\end{array}$ & Enter value 1-5 \\
\hline $\begin{array}{l}\text { What material was review } \\
\text { from what you knew before } \\
\text { taking this course? }\end{array}$ & Qualitative Answer \\
\hline
\end{tabular}

\section{Appendix B: Qualitative Responses}

- "Due to such I went to the additional extra help sessions, attended al tutorials and went to prof office hours. Unfortunately, this did not help make up for the lack of time I had available to dedicate to learning the broad range of new materials."

- "I tried to join the SEA (sustainable engineers association) mentorship program and design team but after a few weeks was unable to attend as i felt I had too much work to do and not enough time for that club. "

- $\quad$ "My appetite was greatly reduced, I developed very poor sleep patterns and was unable to destress. "“ 